\title{
Characterizing the Effects of Hot Isostatic Pressing on IN713C Superalloy Blade Microstructure by Electron Backscatter Diffraction
}

\author{
B. Chmiela*, B. Kościelniak and S. Roskosz \\ Institute of Materials Science, Faculty of Materials Engineering and Metallurgy, Silesian University of Technology, \\ Katowice, Poland
}

\begin{abstract}
The integrity of turbine blades is essential for the safe operation of jet engines. Thus, the mechanical properties, especially creep resistance and fatigue strength at high temperatures, must be thoroughly optimized. In particular, it has previously been observed that the mechanical properties of blades depend on the microstructure and porosity resulting from the casting process. To decrease the internal porosity generated by investment casting, hot isostatic pressing can be applied. This paper aims to evaluate the effects of hot isostatic pressing on the microstructure of IN713C alloy blades. Two variants of hot isostatic pressing treatment, differing in pressure, were carried out, and each resulted in lowered porosity. Microstructural investigations, performed using scanning electron microscopy and electron backscatter diffraction revealed significant changes of $\gamma^{\prime}$ particles and high strain intensity in the surface layer of the blades after hot isostatic pressing treatment.
\end{abstract}

DOI: 10.12693/APhysPolA.130.1097

PACS/topics: 61.66.Dk, 07.20.Pe, 81.40.Vw, 61.05.jd

\section{Introduction}

Nickel-based superalloys are widely used in the aerospace industry for manufacturing turbine blades. Turbine blades operate at extreme conditions in jet engines, including very high temperatures over $1200 \mathrm{~K}$, high pressures and corrosive environments [1,2]. Therefore, excellent mechanical properties including very high creep resistance and high fatigue strength at high temperature, must be shown and understood via rigorous characterization methods [1-3]. The mechanical properties depend on the microstructure (obtained by performing solution heat treatment and aging) and casting defects [4]. The most common casting defect is porosity [1-4]. In particular, porosity strongly decreases the fatigue strength, therefore the relative volume of the pores should be as low as possible, and one of the most effective techniques for the reduction and/or elimination of porosity and even healing creep cavities is hot isostatic pressing (HIP) [5-8]. In the HIP process, high temperatures and hydrostatic pressures are applied to densify the material. The most important parameter for determining the initial temperature of the solution heat treatment is the $\gamma^{\prime}$-solvus temperature. Nickel-based superalloys are precipitationstrengthened materials with a high relative volume of the $\gamma^{\prime}$ phase $\left(\mathrm{Ni}_{3}(\mathrm{Al}, \mathrm{Ti})\right)$, and HIP is usually performed at a temperature slightly below the $\gamma^{\prime}$-solvus temperature [8]: typical conditions for HIP of nickel-based superalloys are $150 \div 175 \mathrm{MPa}$ for $2 \div 4 \mathrm{~h}[5,6]$.

This paper reports the effect of HIP treatment on the microstructure of turbine blades made of the IN713C

\footnotetext{
*corresponding author; e-mail: bartosz.chmiela@polsl.pl
}

nickel-based superalloy (widely used due to its relatively low cost and good mechanical properties). In order to investigate the effects of HIP parameters on microstructural evolution, two different pressures were applied during HIP.

\section{Experimental}

Three polycrystalline turbine blades (with equiaxed grains) were used in this study. The blades were made of the IN713C nickel-base superalloy, which chemical composition is shown in Table 1. One blade was characterized in the as-cast state, but the other blades were subjected to two different HIP processes: in the first variant of HIP the pressure was $20 \mathrm{MPa}$ lower than in the second.

TABLE I

Chemical composition of IN713C superalloy [wt. \%].

\begin{tabular}{c|c|c|c|c|c|c|c|c}
\hline \hline $\mathrm{Ni}$ & $\mathrm{Cr}$ & $\mathrm{Mo}$ & $\mathrm{Nb}$ & $\mathrm{Al}$ & $\mathrm{Ti}$ & $\mathrm{C}$ & $\mathrm{B}$ & $\mathrm{Zr}$ \\
\hline bal. & 12.5 & 4.2 & 2 & 6 & 0.8 & 0.12 & 0.012 & 0.1
\end{tabular}

For microstructural characterization, the samples were sectioned from the mid-airfoil areas, perpendicular to the blade axis. The samples were prepared according to procedure described earlier [9-11]. After ultrasonic cleaning, electrochemical etching in 10\% oxalic acid solution (voltage: $6 \mathrm{~V}$, time: $5 \mathrm{~s}$ ) was applied. Microstructural investigations were performed using Hitachi S-3400N scanning electron microscope (SEM), equipped with energy dispersive X-ray spectrometer (EDS) (Thermo Noran). Moreover, electron backscatter diffraction (EBSD, INCA HKL Nordlys II with Channel 5 software) analysis very close to the suction side of the blades were carried out with a step size of about $1 \mu \mathrm{m}$. For EBSD analysis, samples were 
additionally polished using an alumina suspension (grit size: $0.05 \mu \mathrm{m})$ for $5 \mathrm{~h}$ with vibration. The determination of internal porosity was carried out on polished samples by image analysis based on optical micrographs (using an Olympus GX-70 light microscope) in accordance with procedures described in literature [9-11].

\section{Results and discussion}

The as-cast blade was characterized by high shrinkage porosity; pores are visible in the interdendritic areas (Fig. 1a). After HIP treatment, the porosity was significantly reduced (Fig. 1b).
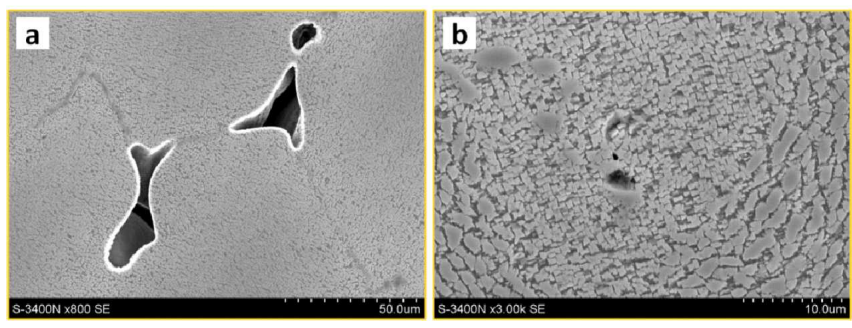

Fig. 1. SEM images of pores in blades made of IN713C: (a) as-cast state; (b) 2nd variant of HIP.

In the as-cast state, the porosity of the blade was $0.138 \%$. Application of HIP reduced the porosity of the blade to $0.018 \%$ in the 1 st variant and $0.012 \%$ in the 2 nd variant. The average number of pores per $\mathrm{mm}^{2}$ was reduced from 45.9 in the as-cast blade to 13.8 and 3.8 after HIP under different pressures. Additionally, HIP caused the shape coefficient of pores to monotonically increase to values close to 1 , indicating that shape of the pores was more similar to that of ideal spheres (Fig. 2).
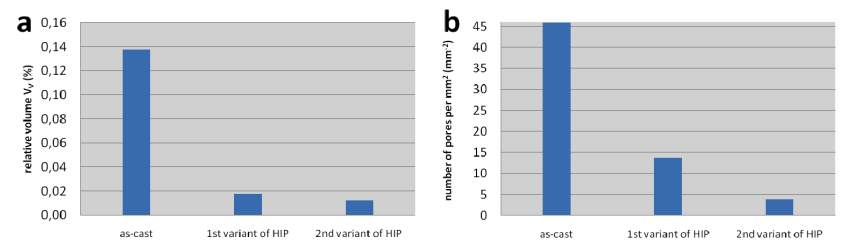

Fig. 2. Distributions of porosity parameters for the three blades: (a) relative volume of pores; (b) number of pores per $\mathrm{mm}^{2}$.

The microstructure of the as-cast blade consists of $\gamma^{\prime}$ particles in $\gamma$ matrix (Fig. 3), primary MC carbides and small amount of $\gamma / \gamma^{\prime}$ eutectics. Inside the dendrites, the $\gamma^{\prime}$ particles are characterized by their cubic shapes with an average edge length of about $0.5 \mu \mathrm{m}$ (Fig. 3a), however, the $\gamma^{\prime}$ particles are irregular in the interdendritic areas (Fig. 3b). HIP treatment leads to some microstructural changes in the blades. The characteristic feature is the change of the $\gamma^{\prime}$ morphology in dendrites, from cubic to irregularly shaped (Fig. 3c).
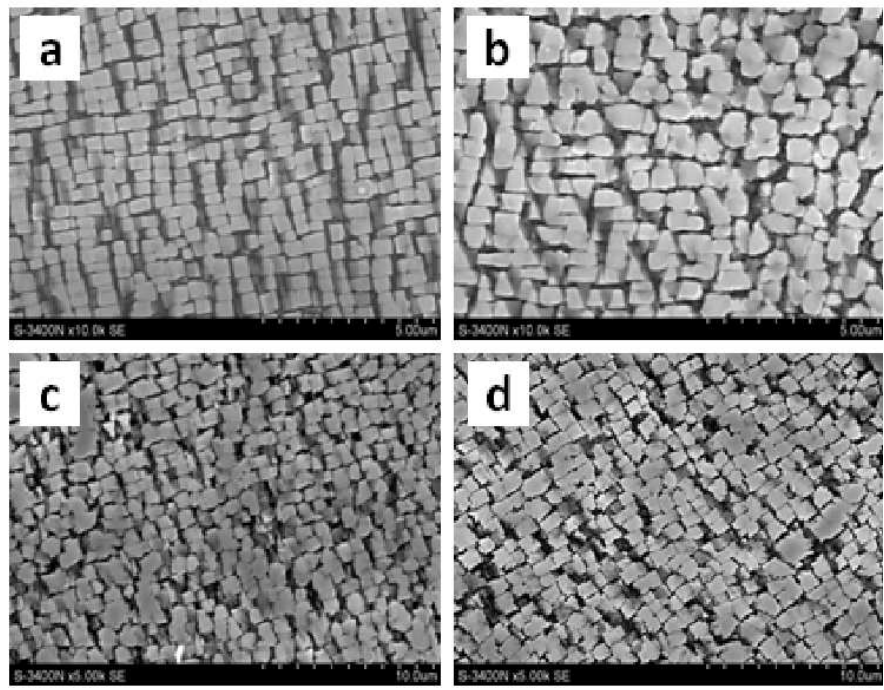

Fig. 3. SEM images of $\gamma^{\prime}$ particles in the blade in the as-cast state $(\mathrm{a}, \mathrm{b})$ and after 2 nd variant of $\operatorname{HIP}(\mathrm{c}, \mathrm{d})$ :

$(\mathrm{a}, \mathrm{c})$ dendrites; $(\mathrm{b}, \mathrm{d})$ interdendritic area.

Moreover, it is known that the $\gamma^{\prime}$ particles can precipitate in the $\gamma$ matrix during gradual cooling below the $\gamma^{\prime}$ solvus temperature [12]. To estimate the extent of deformation (strain) after HIP treatment, EBSD analysis on the basis of strain contouring maps (SC) was performed. The strain contouring map was formed as follows: software measured the maximum misorientation between any two points in a grain and weighted the grain according to the misorientation value. The EBSD investigation was carried out very close to the surface of the suction side of the blades. The strain contouring maps were overlaid on the band contrast maps (BC) and the orientation maps to find relationships between grain orientation and strain intensity after HIP (BC is an image quality factor derived from the Hough transformation which describes the average intensity of the Kikuchi bands with regard to the overall intensity within the area of interest). Figure 4a shows the orientation map (inverse pole IPF colour scheme) and Fig. 4b shows the strain contouring map overlaid on the band contrast map for the blade in the as-cast state. High angle grain boundaries (HABs) with misorientations higher than $15^{\circ}$ Care presented as thick black lines. A very small amount of low angle boundaries (LABs, highlighted as thin black lines) are close to the blade surface (Fig. 4a). There are few weakly deformed areas; strain likely remained after solidification (Fig. 4b).

Orientation maps for blades after HIP treatment are presented in Fig. 5. In contrast to the as-cast blade, many low angle boundaries formed close to the surface of the blades (suction side) due to the high pressure during HIP. Strain contouring maps revealed that the most strained areas are close to the surfaces of the blades (Fig. 6). The highest strain intensity is about $10 \div 20 \mu \mathrm{m}$ from the blades surface. It is worthy of note that the areas with the highest strain intensity are not continuous; they do 

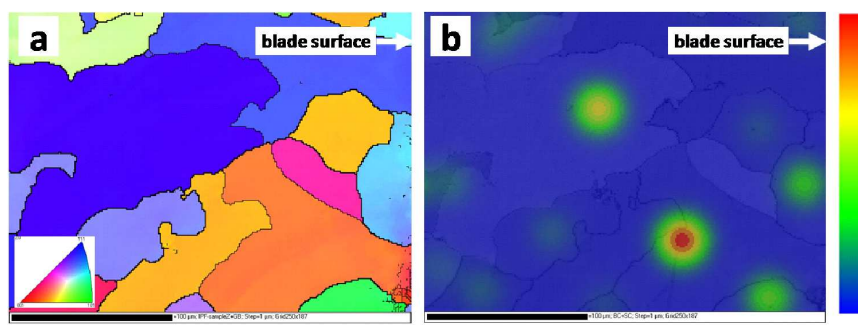

Fig. 4. Orientation map (IPF) (a) and BC/SC map (b) for the as-cast blade.

not form continuous zones along the surface layer. This is related to the variation in the Young moduli; present in particular between grains depending on their crystallographic orientation [13]. For nickel-based superalloys, the highest value of Young's modulus is along the [111] direction, followed by the $[110]$ direction and the lowest is in the [001] direction [13]. Thus, the highest strain intensity was detected in the grains with [001] or [101] directions perpendicular to the surface of the blades.

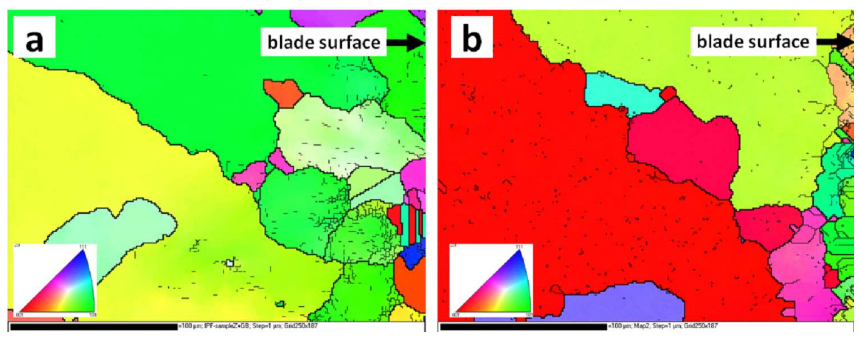

Fig. 5. Orientation maps (IPF) with highlighted grain boundaries: (a) 1st variant of HIP; (b) 2nd variant of HIP.
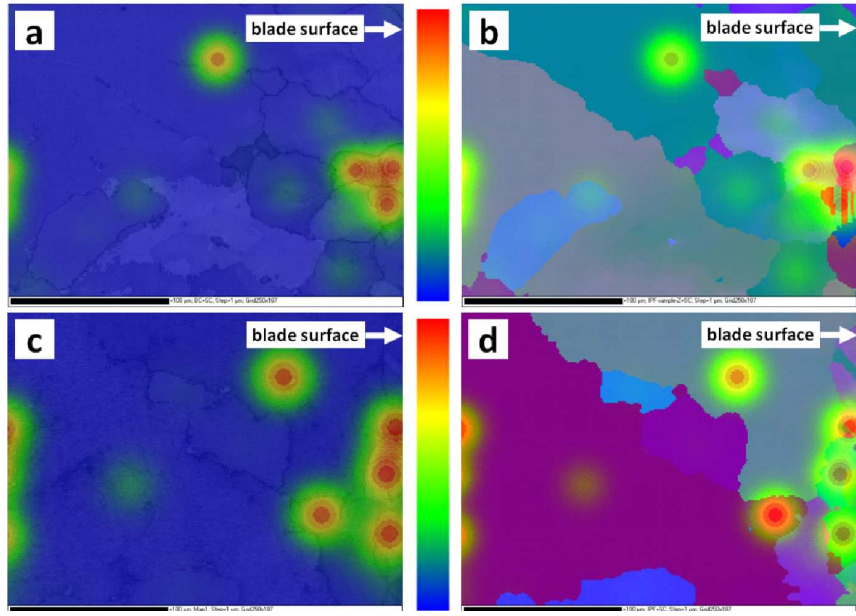

Fig. 6. BC/SC maps (a,c) and IPF/SC maps (b,d) for blades after HIP.

\section{Summary and conclusions}

HIP is a useful method for the elimination of internal porosity of turbine blades made of nickel-based superalloys. In comparison to the as-cast blade, which exhibited porosity of about $0.138 \%$, the porosity was reduced to $0.018 \%$ after the 1 st variant of HIP and to $0.012 \%$ after the 2 nd variant of HIP. Higher pressures caused significant reductions of the relative volumes of the pores. Additionally, HIP treatments caused microstructural changes, especially in the $\gamma^{\prime}$ morphology, with irregularly shaped $\gamma^{\prime}$ particles in the dendrites. EBSD analysis revealed high strain intensity in the surface layer of the blades, which may be important for their mechanical properties. The effects of these microstructural changes on the mechanical properties of blades should be further investigated.

\section{Acknowledgments}

Project co-financed by the European Regional Development Fund under the Operational Programme Innovative Economy and the National Centre for Research and Development Poland (NCBiR) Grant No. INNOLOT/I/8/NCBR/2013 (2013-2018) - INNOCAST.

\section{References}

[1] R.C. Reed, Superalloys. Fundamentals and Applications, Cambridge University Press, Cambridge 2006.

[2] M. Durand-Charre, The Microstructure of Superalloys, Gordon and Breach Sci. Publ., Amsterdam 1997.

[3] Superalloys. A technical guide, Eds. M.J. Donachie, S.J. Donachie, ASM International, Materials Park (OH) 2002.

[4] Modelling for Casting and Solidification Processing, Ed. Yu Kuang-O (Oscar), Marcel Dekker, New York 2002.

[5] L. Kunz, P. Lukáš, R. Konečná, S. Fintová, Int. J. Fatigue 41, 47 (2012).

[6] S.-H. Chang, J. Alloys Comp. 486, 716 (2009).

[7] K.-O. Lee, S.-B. Lee, Mater. Sci. Eng. A 541, 81 (2012).

[8] Y. Zhou, S. Rao, Z. Zhang, Z. Zhao, Mater. Des. 49, 25 (2013).

[9] S. Roskosz, M. Staszewski, J. Cwajna, Mater. Charact. 56, 406 (2006).

[10] S. Roskosz, J. Adamiec, Mater. Charact. 60, 1120 (2009).

[11] S. Roskosz, Comprehensive Evaluation of Porosity of Precision Castings Made of High-Temperature Creep Resisting Nickel Superalloys, Silesian University of Technology Publ. Co., Gliwice 2011 (in Polish).

[12] S. Zlá, B. Smetana, M. Žaludová, J. Dobrovská, V. Vodárek, K. Konečná, V. Matějká, H. Francová, J. Thermal Anal. Cal. 110, 211 (2012).

[13] H. Takagi, M. Fujiwara, K. Kakehi, Mater. Sci. Eng. A 387, 348 (2004). 